\title{
Suppression of Melanin Synthesis by the Phenolic Constituents of Sappanwood (Caesalpinia sappan)
}

\author{
Authors \\ Kaoru Mitani ${ }^{1}$, Fumihide Takano ${ }^{1,2}$, Tetsuro Kawabata ${ }^{1}$, Ahmed E. Allam ${ }^{1}$, Mayumi Ota ${ }^{1}$, Tomoya Takahashi ${ }^{1}$, \\ Nobuo Yahagi ${ }^{1}$, Chikai Sakurada ${ }^{2}$, Shinji Fushiya ${ }^{2}$, Tomihisa Ohta ${ }^{1}$ \\ Affiliations \\ ${ }^{1}$ Pharmacognosy and Chemistry of Natural Products, School of Pharmacy and Pharmaceutical Sciences, Kanazawa University, \\ Kanazawa, Japan \\ ${ }^{2}$ Nihon Pharmaceutical University, Saitama, Japan
}

\author{
Key words \\ - Caesalpinia sappan Linn. \\ - Fabaceae \\ - antimelanogenesis \\ - brazilin \\ - mRNAs expression
}

\begin{abstract}
$\nabla$

Sappanwood (Caesalpinia sappan Linn.) is used as an herbal medicine. It is sometimes used to treat skin damage or as a facial cleanser. In the present study, the methanol (MeOH) extract of sappanwood was found to inhibit melanin synthesis in cultured human melanoma HMV-II cells stimulated with forskolin, and six active compounds (1-5 and 7) were isolated from the extract along with a non-active compound (6). Compounds 2-7 were identified as sappanchalcone (2), 3'-deoxy-4-Omethylsappanol (3), brazilein, (4), brazilin (5), sappanol (6), and 4-0-methylsappanol (7). Compound 1 was a new compound, and its structure was determined to be $(6 \mathrm{a} S, 11 \mathrm{~b} R)-7,11 \mathrm{~b}$-dihydro$6 H$-indeno[2,1-c]chromene-3,6a,10,11-tetrol by spectroscopic analyses. Among the six active
\end{abstract}

\section{Introduction}

Melanin is a biopigment synthesized in melanosomes. Melanosomes enclosing melanin polymers are transferred from melanocytes to surrounding keratinocytes in the human epidermis. The color of human skin is determined primarily by the quantity, type, and distribution of melanin in keratinocytes [1,2]. Melanin has a critical role in the protection of the skin from solar ultraviolet (UV) radiation [3], but excess synthesis of melanin leads to hyperpigmentation disorders such as melasma, lentigo, and age spots [4]. Hence, the inhibitors of melanin biosynthesis have received considerable attention in clinical and cosmetic research, and melanin inhibitors such as hydroquinone [5], kojic acid [6,7], arbutin $[8,9]$, and linoleic acid $[10,11]$ have been discovered.

"Sappan Lignum" is the heartwood of sappanwood (Caesalpinia sappan Linn.; Fabaceae) and is used both as a dyestuff and as an herbal medicine compounds, brazilin (5) $\left(\mathrm{EC}_{50}: 3.0 \pm 0.5 \mu \mathrm{M}\right)$ and 4-O-methylsappanol (7) (EC $50: 4.6 \pm 0.7 \mu \mathrm{M})$ strongly suppressed melanin synthesis in HMV-II cells. Bioactive compounds showed moderate cytotoxicities against HMV-II cells with $\mathrm{IC}_{50}$ values of $83.1 \pm 4.0 \mu \mathrm{M}$ (for 2 ), $72.0 \mu \mathrm{M} \pm 2.4$ (for 3 ), $33.8 \pm 1.1 \mu \mathrm{M}$ (for 4 ), $18.4 \pm 0.8 \mu \mathrm{M}$ (for 5 ), and $20.2 \pm 0.8$ (for 7), respectively. Brazilin (5) selectively suppressed the expression of mRNAs for tyrosinase-related protein (TYRP) 2 and tyrosinase but did not influence the expression of TYRP1. These results suggest that brazilin (5) is a new class of melanin inhibitor and that sappanwood could be used as a cosmetic material.

Supporting information available online at http://www.thieme-connect.de/ejournals/toc/ plantamedica
[12]. It has been used to treat wounds, skin diseases, leprosy, dysentery, menorrhagia, menoxenia, leukorrhea, and diabetic complications [13]. Several pharmacological studies have been undertaken focusing on the extracts and constituents of this plant as well as on the various activities found (e.g., immunomodulatory, [14], antiinflammatory [15], antioxidant [16], hypoglycemic [17], vasorelaxant [12], spasmolytic [18], and anti-arthritic [19] effects). However, the effect on melanin synthesis of the extracts and constituents of this plant has not been studied in detail. In the present study, we investigated the inhibitory effects of the methanol $(\mathrm{MeOH})$ extract of sappanwood on melanin synthesis in human melanoma HMV-II cells stimulated with forskolin. The $\mathrm{MeOH}$ extract showed inhibitory activity, and six compounds (one of which is novel) were isolated as active principles from the extract. Furthermore, the mechanism of action for the most potent inhibitory compound, brazilin $\mathbf{5}$, was investigated. 


\section{Materials and Methods}

$\nabla$

General

Values for optical rotation were determined with a Horiba SEPA3000 high-sensitivity polarimeter (Horiba). UV data were obtained with a Shimadzu UV-1600 UV-visible spectrometer (Shimadzu). IR data were obtained with a Shimadzu IR-460 IR spectrophotometer. Circular dichroism (CD) data were obtained using a JASCO J-820 spectrometer (JASCO).

NMR spectra were recorded with a JEOL GSX-500 spectrometer (JEOL) in acetone- $d_{6}$ and dimethyl sulfoxide (DMSO)- $d_{6}$. Chemical shifts were referenced to the residual solvent peaks acetone- $d_{6}$ $\left(\delta_{\mathrm{H}} 2.04\right.$ and $\left.\delta_{\mathrm{C}} 29.8\right)$ and DMSO- $d_{6}\left(\delta_{\mathrm{H}} 2.49\right.$ and $\left.\delta_{\mathrm{C}} 39.5\right)$. Mass spectra were measured on a JEOL SX-102 mass spectrometer. Reversed-phase high-performance liquid chromatography (HPLC) was performed on an ODS column (particle size: $5 \mu \mathrm{m}$, TOSO, $18 \mathrm{~mm} \times 250 \mathrm{~mm})$. Silica gel $(63-210 \mu \mathrm{m}$; Kanto Kagaku) and ODS (63-212 $\mu \mathrm{m}$; Wako Pure Chemical Industries) were used for open-column chromatography. Thin-layer chromatography (TLC) was done on silica gel $60 \mathrm{~F}_{254}$ (Merck) and RP-18 $\mathrm{F}_{254 \mathrm{~S}}$ (Merck).

\section{Plant material}

C. sappan for medicinal use (lot number: 313116 ) was purchased from Uchida Wakanyaku Co. Ltd. and identified by the authors. A voucher specimen of the plant material (T-232) was deposited in the Laboratory of the Pharmacognosy and Chemistry of Natural Products, School of Pharmacy and Pharmaceutical Sciences, Kanazawa University (Kanazawa, Japan).

\section{Extraction and isolation}

The air-dried heartwood of C. sappan $(5.0 \mathrm{~kg})$ was extracted thrice with $\mathrm{MeOH}(3 \mathrm{~L})$ at room temperature. The $\mathrm{MeOH}$ solution (9L) was passed through filter paper (Advantec MFS, Inc.), and the solvent removed under reduced pressure at $35^{\circ} \mathrm{C}$ to yield the $\mathrm{MeOH}$ extract ( $408 \mathrm{~g}$ ). The $\mathrm{MeOH}$ extract ( $390 \mathrm{~g}$ ) was suspended in $\mathrm{H}_{2} \mathrm{O}$ and partitioned successively with $n$-hexane $(1 \mathrm{~L} \times 3)$, ethylacetate $($ EtOAc $)(1 \mathrm{~L} \times 5)$, and $n$-butanol $(n-\mathrm{BuOH})$ $(1 \mathrm{~L} \times 3)$, respectively, to give $n$-hexane $(9.46 \mathrm{~g})$, EtOAc (345 g), $n$ $\mathrm{BuOH}$ (17.4 g), and $\mathrm{H}_{2} \mathrm{O}$ (22.7 g) fractions.

The EtOAc fraction was further separated by column chromatography $(80 \mathrm{~mm} \times 200 \mathrm{~mm})$ on $\mathrm{SiO}_{2}$, eluted with a gradient of $n$ hexane and EtOAc ( $n$-hexane: EtOAc $=5: 5 \rightarrow 4: 6 \rightarrow 2: 8 \rightarrow$ EtOAc) and $\mathrm{MeOH}$ to afford six fractions. The third fraction $(54.0 \mathrm{~g}$, eluted by $n$-hexane: $E$ tOAc $=2: 8$ ) was subjected to additional column chromatography on $\mathrm{SiO}_{2}$ and eluted with a gradient of chloroform and methanol $\left(\mathrm{CHCl}_{3}: \mathrm{MeOH}=14: 1 \rightarrow 9: 1 \rightarrow 7: 1 \rightarrow 5: 1 \rightarrow\right.$ $\mathrm{MeOH})$ to give nine fractions. A part of the fraction eluted by $\mathrm{CHCl}_{3}: \mathrm{MeOH}(14: 1)$ (20 mg) was purified by HPLC on a $\mathrm{SiO}_{2}$ column (TOSO; $18 \mathrm{~mm} \times 250 \mathrm{~mm}$; particle size, $5 \mu \mathrm{m}$; flow rate, $5 \mathrm{~mL} / \mathrm{min})$ with the eluting solvent $\left(\mathrm{CHCl}_{3}: \mathrm{MeOH}=97: 3\right)$ to give compound 2 ( $6.04 \mathrm{mg}$; purity $>91 \%)$. A further portion of the same fraction $\left(80 \mathrm{mg}\right.$ ) was also separated by $\mathrm{HPLC}$ on a $\mathrm{SiO}_{2}$ column with the eluting solvent $\left(\mathrm{CHCl}_{3}: \mathrm{MeOH}=14: 1\right)$ to give compound 3 (2.21 mg; purity $>90 \%$ ). A further portion of the same fraction $(850 \mathrm{mg})$ was subjected to ODS column $(80 \mathrm{~mm} \times$ $200 \mathrm{~mm}$ ) chromatography with elution with a gradient of aqueous acetonitrile solution $(10 \% \rightarrow 25 \% \rightarrow 40 \% \rightarrow 70 \% \rightarrow 100 \%)$ to give seven fractions. The fraction eluted by $25 \%$ aqueous acetonitrile was purified by HPLC on an ODS column by elution with the same aqueous acetonitrile solvent to afford compound $\mathbf{4}$ $(1.79 \mathrm{mg}$; purity $>90 \%)$. The fraction eluted by $\mathrm{CHCl}_{3}$; $\mathrm{MeOH}$ $(14: 1)(3.7 \mathrm{~g})$ was separated further by HPLC on a preparative
ODS column with the eluting aqueous acetonitrile solvent system $(10 \% \rightarrow 25 \% \rightarrow 40 \% \rightarrow 100 \%)$. Compound 5 ( 2.99 g; purity $>90 \%)$ was purified from the fraction eluted by $10 \%$ aqueous acetonitrile. Compounds 6 ( $3.97 \mathrm{mg}$; purity $\approx 92 \%$ ) and 7 ( $16.0 \mathrm{mg}$; purity $>92 \%$ ) were separated from the fraction eluted by $25 \%$ aqueous acetonitrile. A new compound 1 (15 mg; purity > 93\%) was obtained from the fraction eluted by $40 \%$ aqueous acetonitrile.

Compounds 2-7 ( $\bullet$ Fig. 1) were isolated and identified as sappanchalcone (2), 3'-deoxy-4-O-methylsappanol (3), brazilein (4), brazilin (5), sappanol (6), and 4-O-methylsappanol (7) by comparison of their spectral data with those reported in the literature [20-24].

Compound 1: orange needles, $[\alpha]_{\mathrm{D}}^{25}+65.0$ (c 0.75, DMSO); UV $(\mathrm{MeOH}) \lambda_{\max }(\log \varepsilon) 282$ (3.46), 203 (4.31) nm; FABMS (negative) $\mathrm{m} / z 285[\mathrm{M}-\mathrm{H}]^{-}$; HRFABMS (negative) $\mathrm{m} / z 285.0789[\mathrm{M}-\mathrm{H}]^{-}$ (calcd. for $\left.\mathrm{C}_{16} \mathrm{H}_{15} \mathrm{O}_{5}, 285.0763\right)$. $\mathrm{CD}\left(c=2.0 \times 10^{-5} \mathrm{M}, \mathrm{MeOH}\right) \Delta \varepsilon$ (nm): -1.41 (282.0). ${ }^{1} \mathrm{H}$ NMR and ${ }^{13} \mathrm{C}$ NMR data for 1 in acetone$d_{6}$ are shown in $\odot$ Table 1.

\section{Measurement of melanin content in cultured human melanoma HMV-II cells}

Intracellular and extracellular melanin contents in cultured HMV-II human melanoma cells (Dainippon Pharmaceutical Co.) were determined according to methods described previously with minor modification [25-28]. Cells were passed once a week and used between passages 5 and 8. Briefly, cultured HMV-II cells were trypsinized $[0.25 \%$ trypsin and $0.1 \%$ ethylenediamine tetraacetic acid (EDTA) at $37^{\circ} \mathrm{C}$ for $5-10 \mathrm{~min}$ ]. Cells [2.5 $\times 10^{4}$ cells/well in $980 \mu \mathrm{L}$ Dulbecco's modified Eagle's medium (DMEM)] were inoculated with a pipette into 24-well plates and incubated for $24 \mathrm{~h}$ at $37^{\circ} \mathrm{C}$ in a $\mathrm{CO}_{2}$ incubator. After 24 -h incubation, $20 \mu \mathrm{L}$ of sample solution was added to each well, and the 24-well plate incubated for 2 days at $37^{\circ} \mathrm{C}$ in a $\mathrm{CO}_{2}$ incubator. Each sample was tested in triplicate. Test samples were dissolved in dimethyl sulfoxide/ phosphate-buffered saline (DMSO/PBS) and then diluted with DMEM to achieve the appropriate concentrations. The final concentration of DMSO was $0.03 \%$. In the control group, DMSO/PBS $(1: 1, v / v)$ solution diluted with DMEM to $0.03 \%$ of the final DMSO concentration was used instead of the sample solution. We used $\alpha$-arbutin (purity $\geq 98 \%$; Sigma-Aldrich) or kojic acid (purity = 98.0\%; Sigma-Aldrich) as the reference compounds for the inhibition of intracellular and extracellular melanogenesis. HMV-II cells were incubated with tested samples, reference compounds, or vehicle in the absence or presence of phorbol-12myristate-13-acetate (PMA; an activator of protein kinase C) or forskolin (an activator of adenylate cyclase) [29] for $120 \mathrm{~h}$. At the indicated time points, the culture medium was removed with a pipette and assayed for extracellular melanin, as described below. The remaining melanoma cells were trypsinized (0.25\% trypsin and $0.1 \%$ EDTA at $37^{\circ} \mathrm{C}$ for $5-10 \mathrm{~min}$ ) and washed with $100 \mu \mathrm{L}$ PBS. Cells were digested by the addition of $400 \mu \mathrm{L} 1 \mathrm{~N} \mathrm{NaOH}$ and left to stand for $16 \mathrm{~h}$ at room temperature. The optical density (OD) of the resulting solution was measured at $475 \mathrm{~nm}$, and the amount of intracellular melanin calculated. The culture medium was centrifuged $\left(600 \times \mathrm{g}\right.$ for $10 \mathrm{~min}$ at $\left.4^{\circ} \mathrm{C}\right)$. An aliquot of the supernatant $(1 \mathrm{~mL})$ was added to $1 \mathrm{~mL}$ of a mixture of $0.4 \mathrm{M} \mathrm{2-}$ [4-(2-hydroxyethyl)-1-piperazinyl] ethanesulfonic acid (HEPES) buffer (pH 6.8) and ethanol (9:1, v/v). The OD of the resulting solution was measured at $475 \mathrm{~nm}$. The amount of melanin retained in the cells (intracellular melanin) and that secreted into cultured medium (extracellular melanin) were determined separately as described by Kawabata et al. [26]. 


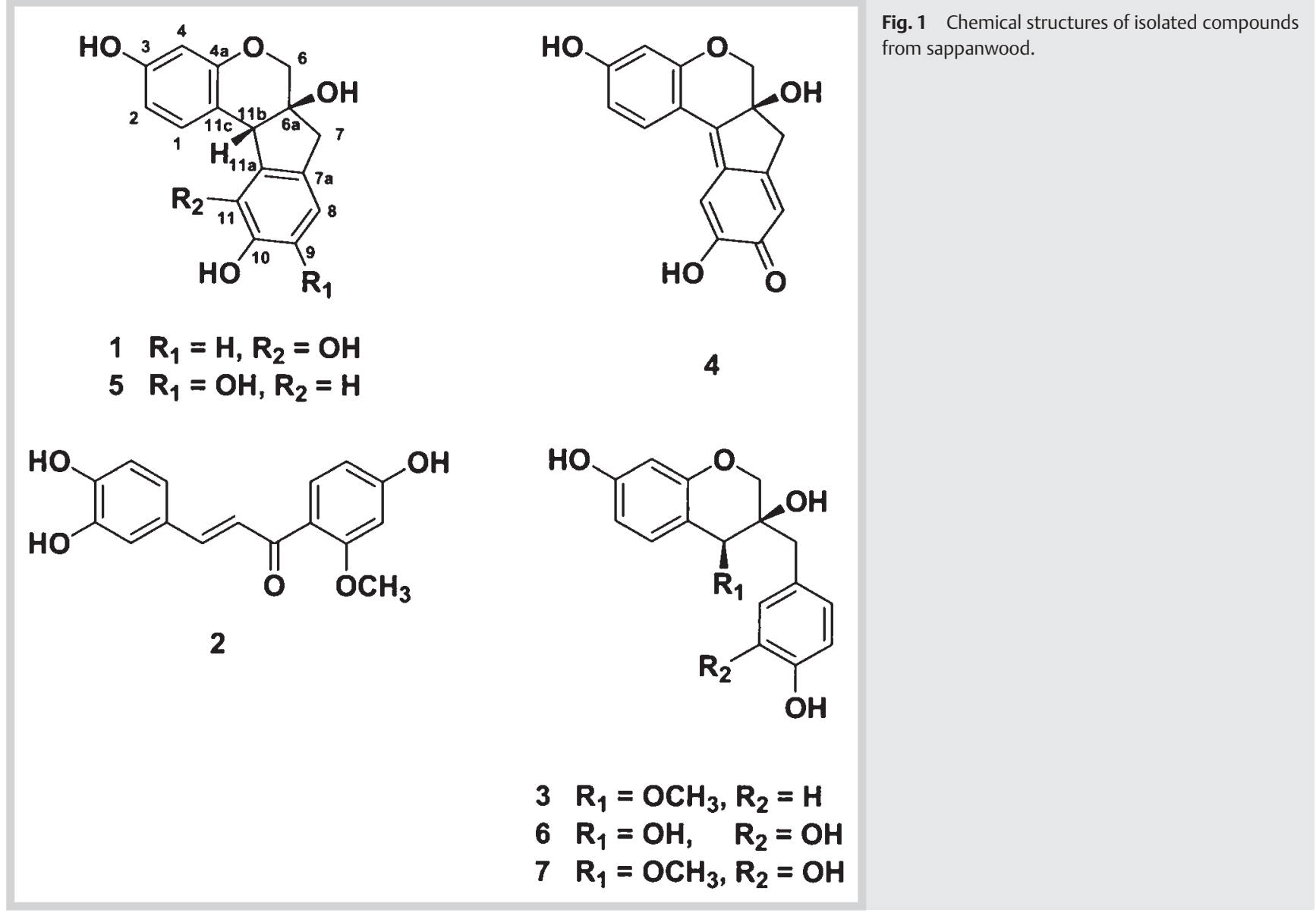

\begin{tabular}{|c|c|c|c|c|}
\hline Position & $\delta_{c}$ & & $\delta_{\mathrm{H}}(\mathrm{in} \mathrm{Hz})$ & HMBC \\
\hline 1 & 132.8 & $\mathrm{CH}$ & $7.72 \mathrm{~d}(8.2)$ & $2,4,4 a$ \\
\hline 2 & 110.2 & $\mathrm{CH}$ & $6.35 \mathrm{dd}(2.0,8.9)$ & 3,4 \\
\hline 3 & 157.4 & $\mathrm{qC}$ & & \\
\hline 4 & 103.6 & $\mathrm{CH}$ & $6.25 d(2.0)$ & $2,3,4 a, 11 c$ \\
\hline $4 a$ & 155.0 & $\mathrm{qC}$ & & \\
\hline 6 & 70.4 & $\mathrm{CH} 2$ & $4.08 d(10.3), 3.85 d(11.0)$ & 4a, 6a, 7, 11b \\
\hline $6 a$ & 79.4 & $\mathrm{qC}$ & $-\mathrm{OH} 5.05^{b}$ & \\
\hline 7 & 41.7 & $\mathrm{CH} 2$ & $3.21 \mathrm{~d}(15.8), 2.68 \mathrm{~d}(15.8)$ & $6,6 a, 7 a, 8,9,10,11,11 b$ \\
\hline $7 a$ & 134.6 & $\mathrm{qC}$ & & \\
\hline 8 & 116.5 & $\mathrm{CH}$ & $6.47 d(8.2)$ & $7,10,11,11 a, 11 b$ \\
\hline 9 & 114.8 & $\mathrm{CH}$ & $6.62 \mathrm{~d}(8.5)$ & $7 a, 10,11$ \\
\hline 10 & 144.2 & $\mathrm{qC}$ & & \\
\hline 11 & 143.3 & $\mathrm{qC}$ & & \\
\hline $11 a$ & 132.5 & $\mathrm{qC}$ & & \\
\hline $11 b$ & 51.1 & $\mathrm{CH}$ & $4.29 \mathrm{~s}$ & 1, 4a, 6a, 7, 11, 11a, 11c \\
\hline $11 \mathrm{c}$ & 117.8 & $\mathrm{qC}$ & & \\
\hline
\end{tabular}

Table $1{ }^{1} \mathrm{H}$ and ${ }^{13} \mathrm{C}$ NMR data for $1^{\text {a. }}$.

a ${ }^{1} \mathrm{H}$ and ${ }^{13} \mathrm{C}$ NMR for $\mathbf{1}$ were measured in actone- $d_{6}$, ${ }^{\mathrm{b}}$ For detection of the hydroxyl signal of position $6 \mathrm{a} ;{ }^{1} \mathrm{H}$ NMR for $\mathbf{1}$ was measured in DMSO-d $d_{6}$

\section{Cytotoxicity assay}

To determine the cytotoxicity of the tested samples, HMV-II cells $(180 \mu \mathrm{L})$ were seeded on 96 -well plates at $1.0 \times 10^{5}$ cells per well with tested samples (purity $>93 \% ; 20 \mu \mathrm{L}$ in DMSO/PBS) at various concentrations. After 48-h cultivation, supernatants were removed, and adherent (B16F1) or non-adherent (THP-1) cells were incubated with 3-(4,5-dimethylthiazol-2-yl)-2,5-diphenyltetrazolium bromide (MTT; $10 \mu \mathrm{L}, 5 \mathrm{mg} / \mathrm{mL}$ in PBS) for $4 \mathrm{~h}$ and then solubilized with $10 \%(w / v)$ sodium dodecyl sulfate [SDS; in
$60 \%(\mathrm{v} / \mathrm{v})$ dimethyl formamide] solution $(100 \mu \mathrm{L})$ for $10 \mathrm{~h}$. Absorbance was measured at $570 \mathrm{~nm}$ using a microplate reader (Bio-Rad Laboratories, Model 550). Cell viability was calculated by comparing the absorbance with that of the non-treated control culture. A cell growth curve was plotted. Values for the halfmaximal inhibitory concentration $\left(\mathrm{IC}_{50}\right)$ were calculated using simple linear regression. 


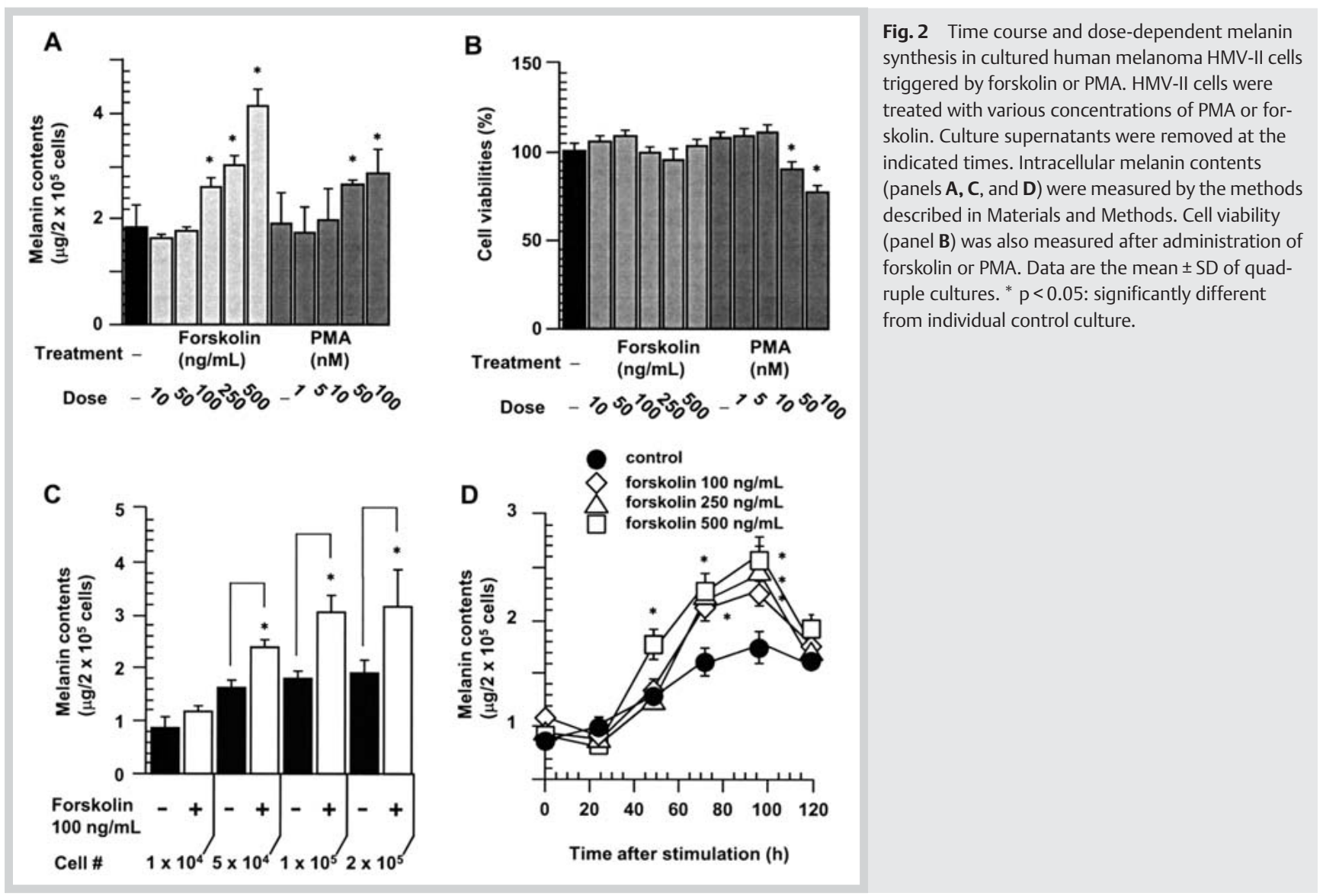

\section{Reverse transcription-polymerase chain reaction (RT-PCR)}

Total ribonucleic acid (RNA) was prepared directly from HMV-II cells administered with samples for $8 \mathrm{~h}$ using a commercially available kit (RNeasy Mini Kit; Qiagen $\mathrm{GmbH}$ ). Isolated RNA was quantified by photometry at $260 \mathrm{~nm} / 280 \mathrm{~nm}$. The quality of RNA was determined by measuring the ratio of $18 \mathrm{~S} / 28 \mathrm{~S}$ ribosomal band intensity in an ethidium bromide containing 1.5\% agarose gel after electrophoresis. A PrimerScript One-step RT-PCR kit ver2 (Takara Bio, Inc.) was used for preparing complementary deoxyribonucleic acid (cDNA). First-strand cDNAs were synthesized by one cycle of reverse transcription at $50^{\circ} \mathrm{C}$ for $30 \mathrm{~min}$ and one cycle of reverse transcriptase incubated at $94^{\circ} \mathrm{C}$ for $2 \mathrm{~min}$. Second-strand cDNAs synthesis and PCR amplification for tyrosinase as well as tyrosinase-related proteins 1 and 2 (TYRP1 and TYRP2, respectively) were carried out at $94^{\circ} \mathrm{C}$ for $30 \mathrm{~s}, 53-57^{\circ} \mathrm{C}$ for $30 \mathrm{~s}$, and $72^{\circ} \mathrm{C}$ for $1 \mathrm{~min}$. For each combination of primers, the kinetics of the PCR amplification was determined beforehand and semiquantitative PCR undertaken in the exponential range. The $\beta$-actin (ACT) gene was used as an endogenous internal standard and amplified with specific primers simultaneously. PCR products were subjected to electrophoresis in $1 \%$ agarose gel and visualized by ethidium bromide staining under UV irradiation. The primer sequences used were: TYR forward, 5'-AGGCAGAGGTTCCTGTCAGA-3' and TYR reverse, 5'-ATTGTGTCTCGTGCTTTGAG-3'; TYRP1 forward, 5'-CATGATGGCGAGAGATGACG-3' and TYRP1 reverse: 5'-TCTGTGAAGGTGTGCAGGAG-3'; TYRP2 forward, 5'-AGTGATTCGGCACGAACATCC-3' and TYRP2 reverse, 5'-CTGGAGGGAAGAAAGGAACC-3'; ACTB forward, 5'-AGAGCTACGAGCTGCCTGAC-3' and ACT reverse, 5'-AGCACTGTGTTGGCGTACAG-3'.

\section{Data analyses}

Mean melanin production $(\mu \mathrm{g} / \mathrm{mL})$ and the percentage of control of melanogenesis are reported as the mean $\pm \mathrm{SD}$ of two or three independent experiments (triplicate/one experiment). Statistical significance was determined by Dunnett's multiple test after one-way analysis of variance (ANOVA) with comparison to a control group. $\mathrm{p}<0.05$ was considered statistically significant.

\section{Supporting information}

Spectroscopic data for compound $\mathbf{1}$ are available as Supporting Information.

\section{Results}

$\nabla$

In the present study, we used human melanoma HMV-II cells instead of the previously used murine melanoma B16F1 cells [26] to assess the inhibitory effect on melanin synthesis. The potential of human melanoma HMV-II cells to synthesize melanin was therefore investigated. Melanin contents in cultured HMV-II cells increased depending upon the concentration of the stimulants forskolin, an activator of adenylate cyclase [30], and PMA, an activator of protein kinase $\mathrm{C}$ ( $\odot$ Fig. 2A). When stimulated by $500 \mathrm{ng} /$ $\mathrm{mL}$ of forskolin, melanin contents increased markedly. Forskolin did not show toxicity at concentrations up to $500 \mathrm{ng} / \mathrm{mL}$, whereas PMA decreased cell viability at $>50 \mathrm{ng} / \mathrm{mL}$ ( $\odot$ Fig. 2 B). On the basis of these data, subsequent experiments were carried out using $500 \mathrm{ng} / \mathrm{mL}$ of forskolin as a stimulant.

The time course of intracellular melanin production in HMV-II cells is shown in $\mathbf{O}$ Fig. 2D. Intracellular production of melanin 


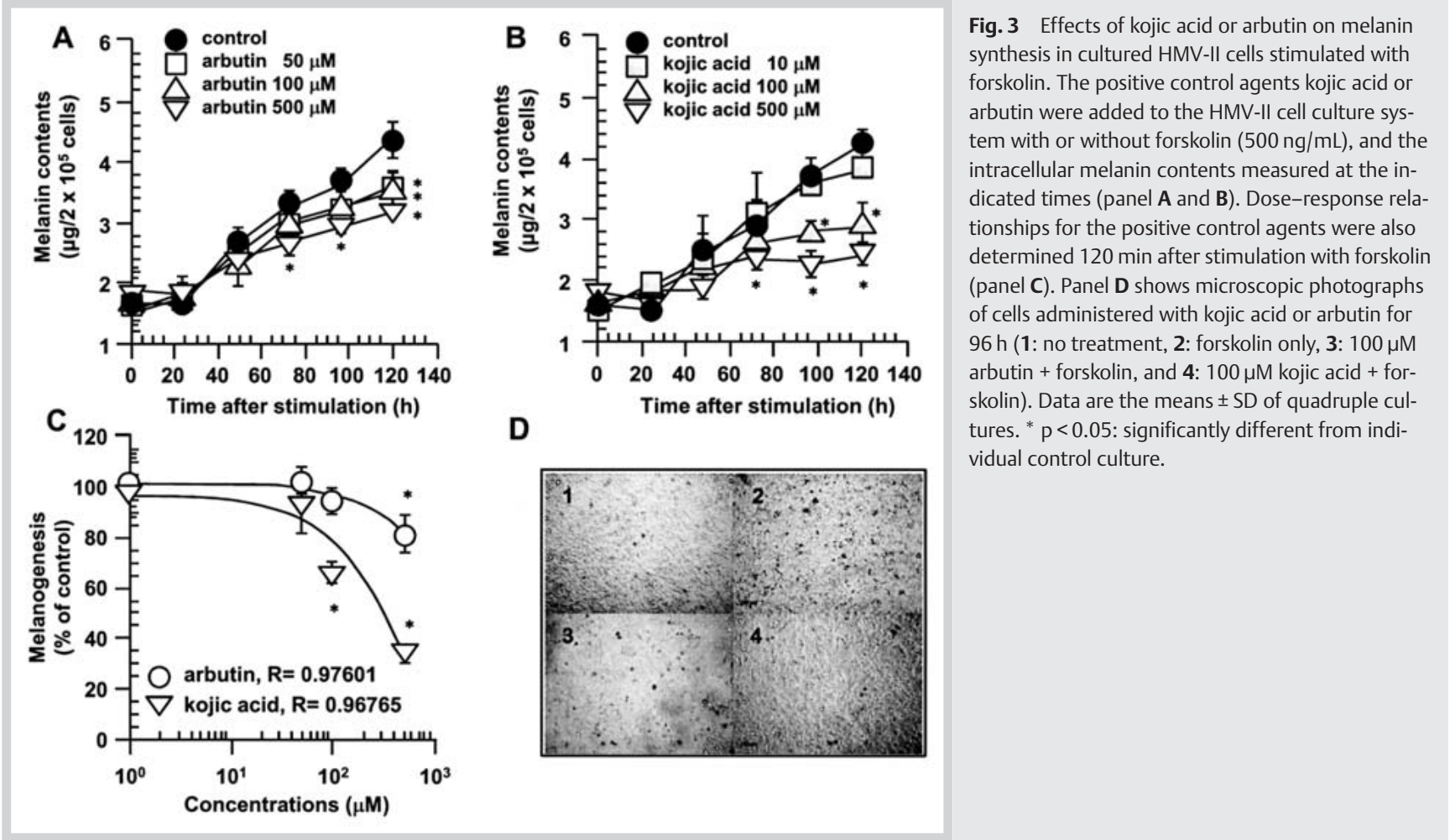

increased appreciably $48 \mathrm{~h}$ after the challenge with $500 \mathrm{ng} / \mathrm{mL}$ forskolin, reached a peak at $96 \mathrm{~h}$ and decreased to the level seen in controls within $120 \mathrm{~h}$. Thus, melanin contents were determined $96 \mathrm{~h}$ after forskolin stimulation in subsequent experiments.

Next, melanin contents in various cell concentrations were measured. Maximal synthesis of melanin was observed at a density of $2 \times 10^{5}$ cells $/ \mathrm{mL}$ (stimulated by $500 \mathrm{ng} / \mathrm{mL}$ forskolin) ( $\odot \mathrm{Fig} .2 \mathrm{C}$ ). At a density of $2 \times 10^{5}$ cells $/ \mathrm{mL}$, cell viability and melanin content decreased (data not shown). Hence, subsequent experiments were carried out using a density of $2 \times 10^{5}$ cells $/ \mathrm{mL}$.

The effects of arbutin and kojic acid [31] as positive control agents to inhibit melanin synthesis were assessed. Arbutin (๑ Fig. 3A) and kojic acid ( $\odot$ Fig. 3B) appreciably reduced the melanin synthesis induced by forskolin at the indicated time points. These inhibitions were concentration-dependent ( Fig. $3 \mathrm{C}$ ). The whitening effect of arbutin and kojic acid could be visualized under a microscope ( $\odot$ Fig. 3D).

Thus, investigation of the inhibitory effect of $C$. sappan was carried out using the in vitro assay system under the conditions mentioned above. The MeOH extract inhibited melanin synthesis by $84.5 \%$ at a $10 \mu \mathrm{g} / \mathrm{mL}$ concentration ( Table 2 ). Furthermore, most of the activity was transferred into EtOAc and $n$-BuOH fractions. The $\mathrm{H}_{2} \mathrm{O}$ fraction also inhibited melanin synthesis but showed marked cytotoxicity.

To identify the active constituent(s), the EtOAc fraction was further separated using $\mathrm{SiO}_{2}$ or ODS column chromatography and HPLC. A new brazilin derivative (1) was isolated along with six known compounds (2-7) identified as sappanchalcone (2), 3'-deoxy-4-O- methylsappanol (3), brazilein (4), brazilin (5), sappanol (6), and 4-0-methylsappanol (7) by analyses of their NMR data and comparison of their spectroscopic data with those in the literature [20-24]. All six known compounds (2-7) were reportedly isolated from sappanwood [20-24].
Compound 1 showed a quasimolecular ion peak at $m / z 285[\mathrm{M}-$ $\mathrm{H}]^{-}$. The molecular formula was determined to be $\mathrm{C}_{16} \mathrm{H}_{13} \mathrm{O}_{5}$ on the basis of HRFABMS and was identical to that of brazilin (5). The NMR data of $\mathbf{1}$ ( Table $\mathbf{1}$ ) were similar with those of brazilin (5) [22], except for two aromatic proton signals. Thus, aromatic proton signals due to ring D at $\delta 6.81(1 \mathrm{H}, \mathrm{s}, \mathrm{H}-8)$ and $\delta 6.92(1 \mathrm{H}$, $\mathrm{s}, \mathrm{H}-11$ ) in brazilin (5) were observed as two doublets at $\delta 6.47$ $(1 \mathrm{H}, \mathrm{d}, J=8.2 \mathrm{~Hz}, \mathrm{H}-8)$ and $\delta 6.62(1 \mathrm{H}, \mathrm{d}, J=8.5 \mathrm{~Hz}, \mathrm{H}-9)$ in $\mathbf{1}$, which indicated that the location of the $\mathrm{OH}$ group at C-9 in brazilin (5) was at C-11 in $\mathbf{1}$. This was supported by analyses of the heteronuclear multiple bound correlation (HMBC) ( Table 1 and Fig. 4A) and also by the correlated spectroscopy (COSY) spectrum (correlation from H-8: $\delta 6.47$ to H-9: $\delta 6.62$ was observed). A significant nuclear Overhauser effect (NOE) correlation ( $\odot$ Fig. 4B) was also observed between $\mathrm{H}-11 \mathrm{~b}$ and the $\mathrm{OH}$ group (C-6a), indicating a cis relationship. Furthermore, the CD spectrum of 1 showed a negative Cotton effect at UV $282 \mathrm{~nm}$ ( Fig. 4C), similar to that of brazilin (5) (data not shown). Thus, compound 1 was determined to be $(6 \mathrm{a} S, 11 \mathrm{bR})-7,11 \mathrm{~b}$-dihydro- $6 H$-indeno[2,1-c] chromene-3,6a,10,11-tetrol.

After establishing the structures, the inhibitory activities of these compounds on melanin synthesis were investigated. Among the seven compounds, brazilin (5) and O-methylsappanol (7) strongly suppressed melanin synthesis in cultured HMV-II cells with concentration values that gave a half-maximal response $\left(\mathrm{EC}_{50}\right)$ of $3.0 \pm 0.5$ and $4.6 \pm 0.7 \mu \mathrm{M}$, respectively. The five compounds $(\mathbf{2}, \mathbf{3}, \mathbf{4}, \mathbf{5}$, and $\mathbf{7})$ showed cytotoxic effects, but selectivity factors ( $\mathrm{IC}_{50} / \mathrm{EC}_{50}$ ) ranging from 1.43 (for 3), 1.82 (for 4), 1.95 (for 2), 4.39 (for 7), to 6.13 (for 5 ) were observed ( Table 3). At a lower concentration, $1 \mu \mathrm{M}$ of brazilin (5) inhibited melanin synthesis by $53 \%$, and the cell viability was $94 \%$.

Interestingly, the inhibitory activity as judged by the half-maximal effective concentration $\left(\mathrm{EC}_{50} ; 61.0 \pm 3.1 \mu \mathrm{M}\right)$ of the new compound (1), an isomer of brazilin (5), was $>20$-times weaker than 
Table 2 Effects of MeOH extract and separated fractions on melanin synthesis in cultured HMV-II cells costimulated with forskolin.

\begin{tabular}{|c|c|c|c|c|c|}
\hline Treatment & Yield (\%) & Concentration $(\mu \mathrm{g} / \mathrm{mL})$ & Inhibition (\%) & Cell viability (\%) & $\mathbf{n}$ \\
\hline \multirow[t]{2}{*}{$\mathrm{MeOH}$ extract } & $8.20^{\mathrm{b}}$ & 1 & $33.2 \pm 1.9$ & $94.3 \pm 0.7$ & 4 \\
\hline & & 10 & $84.5 \pm 13.5^{a}$ & $51.8 \pm 3.1^{\mathrm{a}}$ & 3 \\
\hline \multirow[t]{2}{*}{$n$-hexane fr. } & $2.43^{c}$ & 1 & $-2.0 \pm 2.4$ & $101 \pm 2$ & 4 \\
\hline & & 10 & $0.3 \pm 1.2$ & $99.1 \pm 5.0$ & 4 \\
\hline \multirow[t]{2}{*}{ EtOAc fr. } & $88.5^{c}$ & 1 & $42.7 \pm 2.8^{a}$ & $87.0 \pm 4.2$ & 4 \\
\hline & & 10 & $79.4 \pm 9.0^{\mathrm{a}}$ & $44.4 \pm 3.0^{\mathrm{a}}$ & 4 \\
\hline \multirow[t]{2}{*}{$n$-BuOH fr. } & $4.46^{c}$ & 1 & $30.8 \pm 2.6$ & $89.0 \pm 2.0$ & 4 \\
\hline & & 10 & $78.3 \pm 20.4^{a}$ & $85.2 \pm 4.8$ & 4 \\
\hline \multirow[t]{2}{*}{$\mathrm{H}_{2} \mathrm{O}$ fr. } & $5.82^{c}$ & 1 & $50.4 \pm 12.0^{\mathrm{a}}$ & $48.0 \pm 1.2^{\mathrm{a}}$ & 4 \\
\hline & & 10 & ND & $10.0 \pm 4.2^{\mathrm{a}}$ & 4 \\
\hline Arbutin & - & $100 \mu \mathrm{M}$ & $58.7 \pm 7.5^{a}$ & $92.6 \pm 2.9$ & 3 \\
\hline Kojic acid & - & $100 \mu \mathrm{M}$ & $76.1 \pm 18.0^{\mathrm{a}}$ & $47.2 \pm 6.6^{a}$ & 4 \\
\hline
\end{tabular}

HMV-II cells were treated with two concentrations of test samples for $96 \mathrm{~h}$ and costimulated with forskolin ( $500 \mathrm{ng} / \mathrm{mL})$. After incubation, melanin contents and cell viabilities were measured. Data are the means percent of control \pm SD of 3 or 4 independent experiments. ${ }^{\text {a }} p<0.05$ : significantly different from non-treated control culture. ${ }^{b}$ Yield of the extract is indicated as percent $(w / w)$ of dried plant. ${ }^{c}$ Yield of each fraction was indicated as percent $(w / w)$ of the MeOH extract. ND: not determined

A
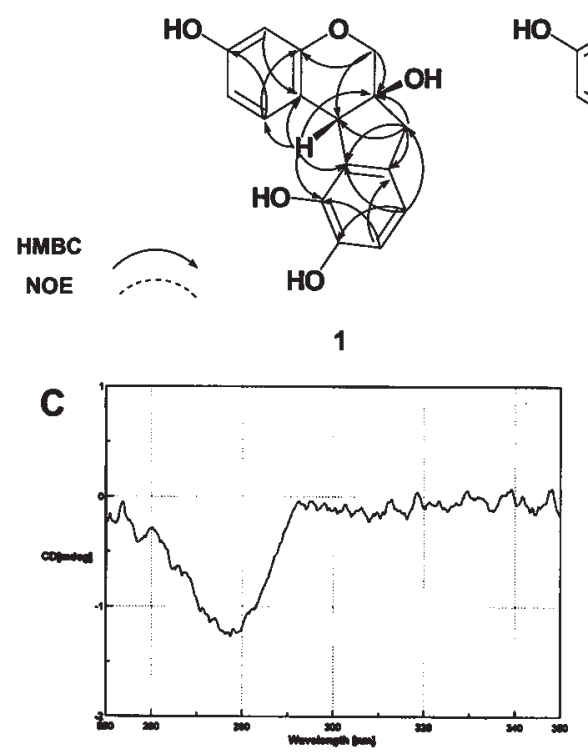

Fig. 4 Key HMBC and NOE correlations and CD spectrum for $\mathbf{1}$.
B

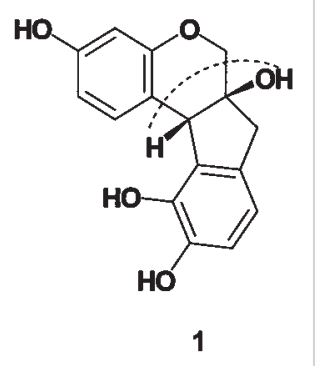

1 


\begin{tabular}{lcll} 
Compound & $\begin{array}{l}\mathrm{EC}_{50} \text { value for anti-melanogenic } \\
\text { activity }(\boldsymbol{\mu M})\end{array}$ & $\begin{array}{l}\mathrm{IC}_{\mathbf{5 0}} \text { value for cytotoxicities } \\
(\boldsymbol{\mu M})\end{array}$ & $\mathbf{n}$ \\
\hline $\mathbf{1}$ & $61.0 \pm 3.1$ & $\mathrm{ND}$ & 8 \\
$\mathbf{2}$ & $42.6 \pm 1.8$ & $83.1 \pm 4.0$ & 8 \\
$\mathbf{3}$ & $50.4 \pm 2.0$ & $72.0 \pm 2.4$ & 8 \\
$\mathbf{4}$ & $18.6 \pm 1.1$ & $33.8 \pm 1.1$ & 8 \\
\hline $\mathbf{5}$ & $3.0 \pm 0.5$ & $18.4 \pm 0.8$ & 8 \\
$\mathbf{6}$ & $>100$ & $\mathrm{ND}$ & 8 \\
$\mathbf{7}$ & $4.6 \pm 0.7$ & $20.2 \pm 0.8$ & 8 \\
\hline Arbutin & $123.3 \pm 3.9$ & $\mathrm{ND}$ & 8 \\
\hline Kojic acid & $70.6 \pm 3.0$ & $99.7 \pm 2.1$ & 8 \\
\hline
\end{tabular}

Table 3 Inhibitory activities of isolated compounds on melanin synthesis in cultured human melanoma HMV-II cells costimulated with forskolin.

Values are mean values from two independent experiments ( $n=4 /$ experiment). Cell viabilities were measured using the MTT method described in Materials and Methods, and $\mathrm{IC}_{50}$ values for individual compounds against HMV-II cells were calculated. ND: not determined

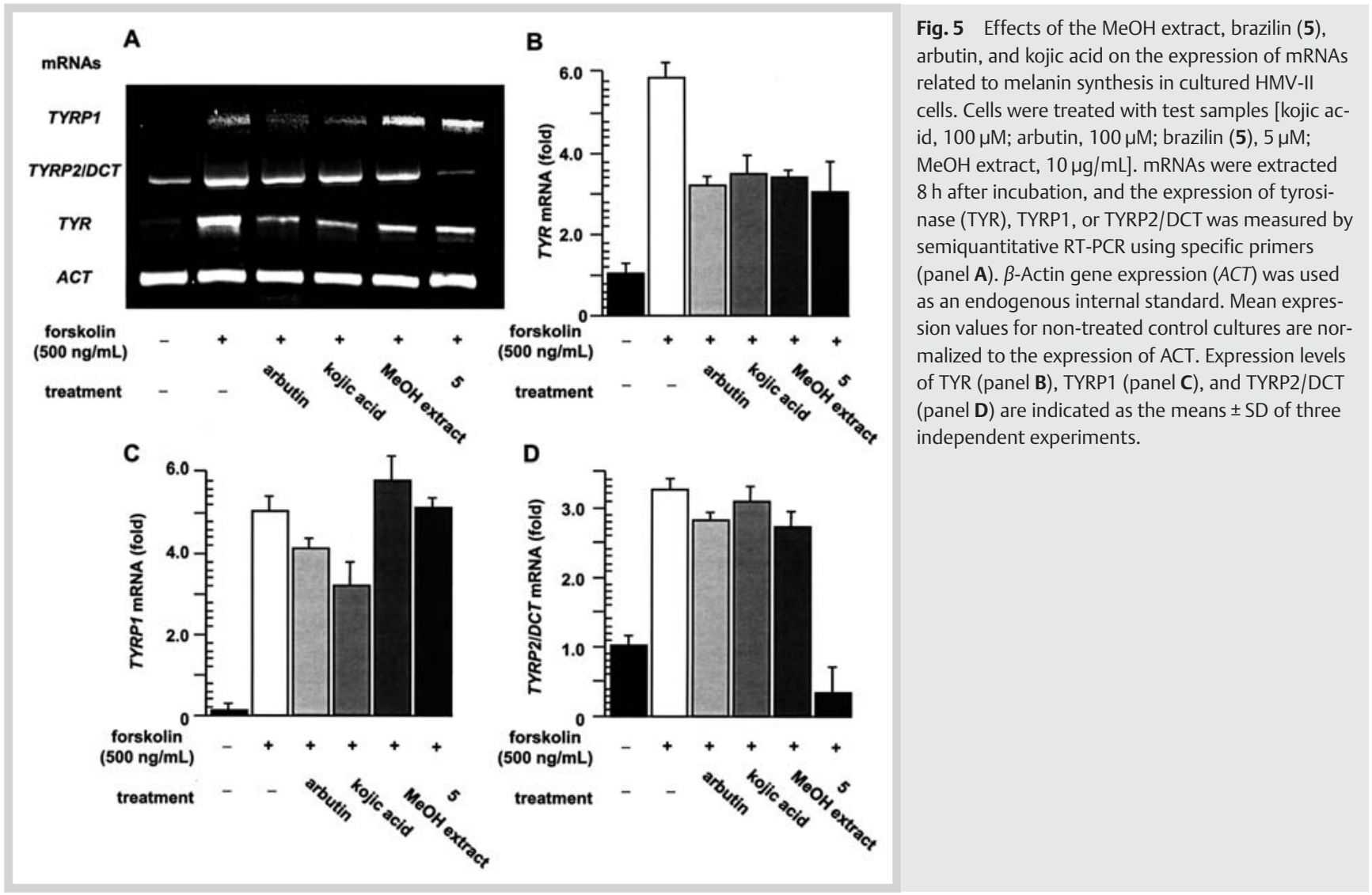

ably not due to their cytotoxicities. We are currently investigating the cytotoxic activity of isolated compounds on cultured human skin melanocytes, keratinocytes, and fibroblast cells to clarify this issue.

In addition, compound $\mathbf{1}$, which is an analog of $\mathbf{5}$, moderately inhibited melanogenesis, suggesting that the position of the benzoyl hydroxyl group is important for inhibition.

To clarify the mechanism of inhibition of brazilin (5), semiquantitative RT-PCR analyses of tyrosinase-related mRNAs in HMV-II cells were carried out. Arbutin and kojic acid suppressed the expression of tyrosinase and TYRP1 mRNAs at $50 \mu \mathrm{M}$. Brazilin (5) $(5 \mu \mathrm{M})$ reduced the expression of tyrosinase and TYRP2 mRNAs, but did not act upon TYRP1 mRNA. Lee et al. [33] reported that the flavanone butin inhibited melanin synthesis in human epidermal melanocytes and suppressed the expression of tyrosi- nase, TYRP1, and TYRP2/DCT mRNAs. Therefore, the mechanism of inhibition of brazilin (5) is different from those of arbutin, kojic acid, and butin.

In the present study, we revealed the suppressive effect of the $\mathrm{MeOH}$ extract of sappanwood upon melanin synthesis in cultured human melanoma HMV-II cells and isolated six active compounds, one of which, compound 7, was a new brazilin analog. We also demonstrated that $\mathbf{5}$, which showed the most potent inhibition, selectively suppressed the expression of mRNAs for tyrosinase and TYRP2. These results support the traditional use of sappanwood for treating skin damage or as a facial cleanser. These compounds are candidates for new cosmetic agents. 


\section{Conflict of Interest}

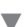

The authors declare no conflict of interest.

\section{References}

1 Parvez S, Kang M, Chung HS, Cho C, Hong MC, Shin MK, Bae H. Survey and mechanism of skin depigmenting and lightening agents. Phytother Res 2006; 20: 921-934

2 Wakamatsu K, Kavanagh R, Kadekaro AL, Terzieva S, Sturm RA, Leachman S, Abdel-Malek Z, Ito S. Diversity of pigmentation in cultured human melanocytes is due to differences in the type as well as quantity of melanin. Pigment Cell Res 2006; 19: 154-162

3 Solano F, Briganti S, Picardo M, Ghanem G. Hypopigmenting agents: an updated review on biological, chemical and clinical aspects. Pigment Cell Res 2006; 19: 550-571

4 Briganti S, Camera E, Picardo M. Chemical and instrumental approaches to treat hyperpigmentation. Pigment Cell Res 2003; 16: $101-110$

5 Jimbow K, Obata H, Pathak MA, Fitzpatrick TB. Mechanism of depigmentation by hydroquinone. J Invest Dermatol 1974; 62: 436-449

6 Mishima Y, Ohyama Y, Shibata T, Seto H, Hatae S. Inhibitory action of Kojic acid on melanogenesis and its therapeutic effect for various human hyper-pigmentation disorders. Skin Res 1994; 36: 134-150

7 Mishima Y, Hatta S, Ohyama Y, Inazu M. Induction of melanogenesis suppression: cellular pharmacology and mode of differential action. Pigment Cell Res 1988; 1: 367-374

8 Maeda K, Fukuda M. Arbutin: mechanism of its depigmenting action in human melanocyte culture. J Pharmacol Exp Ther 1996; 276: 765-769

9 Sugai T. Clinical effects of arbutin in patients with chloasma. Skin Res 1992; 34: 522-529

10 Ando H, Ryu A, Hashimoto A, Oka M, Ichihashi M. Linoleic acid and alpha-linolenic acid lightens ultraviolet-induced hyperpigmentation of the skin. Arch Dermatol Res 1998; 290: 375-381

11 Ando H, Watabe H, Valencia JC, Yasumoto K, Furumura M, Funasaka Y, Oka M, Ichihashi M, Hearing VJ. Fatty acids regulate pigmentation via proteasomal degradation of tyrosinase: a new aspect of ubiquitin-proteasome function. J Biol Chem 2004; 279: 15427-15433

12 Sasaki Y, Suzuki M, Matsumoto T, Hosokawa T, Kobayashi T, Kamata K, Nagumo S. Vasorelaxant activity of sappan lignum constituents and extracts on rat aorta and mesenteric artery. Biol Pharm Bull 2010; 33: $1555-1560$

13 Wu J, Hou B, Zhang MM, Zhou YP, Yu B. Protosappanin A, an immunosuppressive constituent from a Chinese herb, prolongs graft survival and attenuates acute rejection in rat heart allografts. Transplant Proc 2008; 40: 3719-3722

14 Ye M, Xie WD, Lei F, Meng Z, Zhao YN, Su H, Du LJ. Brazilein, an important immunosuppressive component from Caesalpinia sappan L. Int Immunopharmacol 2006; 6: 426-432

15 Hu CM, Liu YH, Cheah KP, Li JS, Lam CSK, Yu WY, Choy CS. Heme oxygenase-1 mediates the inhibitory actions of brazilin in RAW264.7 macrophages stimulated with lipopolysaccharide. J Ethnopharmacol 2009; 121: 79-85
16 Badami S, Moorkoth S, Rai SR, Kannan E, Bhojraj S. Antioxidant activity of Caesalpinia sappan heartwood. Biol Pharm Bull 2003; 26: 15341537

17 Parameshwar S, Srinivasan KK, Rao CM. Oral antidiabetic activities of different extracts of Caesalpinia bonducella seed kernels. Pharm Biol 2002; 40: 590-595

18 Rodriguez-Lopez V, Salazar L, Estrada S. Spasmolytic activity of several extracts obtained from some Mexican medicinal plants. Fitoterapia 2003; 74: 725-728

19 Wang YZ, Sun SQ Zhou YB. Extract of the dried heartwood of Caesalpinia sappan L. attenuates collagen-induced arthritis. J Ethnopharmacol 2011; 136: 271-278

20 Namikoshi M, Nakata H, Saitoh T. Homoisoflavonoids from Caesalpinia sappan. Phytochemistry 1987; 26: 1831-1833

21 Namikoshi M, Nakata H, Saitoh T. Homoisoflavonoids and related compounds. V. A novel dibenzoxocin derivative from Caesalpinia sappan $\mathrm{L}$. Chem Pharm Bull 1987; 35: 3615-3619

22 Kim DS, Baek NI, Oh SR, Jung KY, Lee IS, Lee HK. NMR assignment of brazilein. Phytochemistry 1997; 46: 177-178

23 Hulme AN, McNab H, Peggie DA, Quye A. Negative ion electrospray mass spectrometry of neoflavonoids. Phytochemistry 2005; 66: 2766-2770

24 Fu LC, Huang XA, Lai ZY, Hu YJ, Liu HJ, Cai XL. A new 3-benzylchroman derivative from sappan lignum (Caesalpinia sappan). Molecules 2008; 13: $1923-1930$

25 Sugimoto K, Nishimura T, Nomura K, Sugimoto K, Kuriki T. Inhibitory effects of $\alpha$-arbutin on melanin synthesis in cultured human melanoma cells and a three-dimensional human skin model. Biol Pharm Bull 2004; 27: 510-514

26 Kawabata T, Cui MY, Hasegawa T, Takano F, Ohta T. Anti-inflammatory and anti-melanogenic steroidal saponin glycosides from Fenugreek (Trigonella foenum-graecum L.) seeds. Planta Med 2011; 77: 705-710

27 Bhatnagar V, Srirangam A, Abburi R. In vitro modulation of proliferation and melanization of melanoma cells by citrate. Mol Cell Biochem 1998; 187: 57-65

28 Matsuda H, Kawaguchi Y, Yamazaki M, Hirata N, Naruto S, Asanuma Y, Kaihatsu T, Kubo M. Melanogenesis stimulation in murine B16 melanoma cells by Piper nigrum leaf extract and its lignan constituents. Biol Pharm Bull 2004; 27: 1611-1616

29 D'Orazio JA, Nobuhisa T, Cui R, Arya M, Spry M, Wakamatsu K, Igras V, Kunisada T, Granter SR, Nishimura EK, Ito S, Fisher DE. Topical drug rescue strategy and skin protection based on the role of Mc1 $\mathrm{r}$ in UV-induced tanning. Nature 2006; 443: 340-344

30 Busca R, Ballotti R. Cyclic AMP: a key messenger in the regulation of skin pigmentation. Pigment Cell Res 2000; 13: 60-69

31 Callender VD, St Surin-Lord S, Davis EC, Maclin M. Postinflammatory hyperpigmentation: etiologic and therapeutic considerations. Am J Clin Dermatol 2011; 12: 87-99

32 Tatsuno T, Jinno M, Arima Y, Kawabata T, Hasegawa T, Yahagi N, Takano F, Ohta T. Anti-inflammatory and anti-melanogenic proanthocyanidin oligomers from peanut skin. Biol Pharm Bull 2012; 35: 909-916

33 Lee MH, Lin YP, Hsu FL, Zhan GR, Yen KY. Bioactive constituents of Spatholobus suberectus in regulating tyrosinase-related proteins and mRNA in HEMn cells. Phytochemistry 2006; 67: 1262-1270 